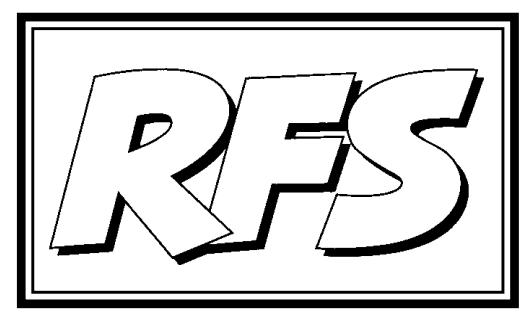

Revista de Fomento Social, 60 (2005), 681-687

\title{
XVIII Reunión del Grupo Fomento Social
}

(Madrid, 12-13 noviembre 2005)

El Grupo Fomento Social se reunió para su encuentro anual en la Casa de Espiritualidad de las Esclavas del Sagrado Corazón, en Madrid (c/ General Martínez Campos), desde el viernes 11 de noviembre por la noche hasta el domingo 13 a mediodía. Los asistentes fueron en total 30, entre ellos el Presidente de la Conferencia de Provinciales de Europa (el belga, P. Mark Rotsaert) y el Provincial de España (P. Elías Royón). La reunión fue coordinada por el nuevo coordinador del Grupo, P. Rafael Yuste, nombrado para ejercer el cargo por un trienio.

El tema escogido en la sesión del año pasado para la de éste era el de los nuevos movimientos sociales y la transformación de la política. A él se dedicó, como es costumbre siempre en este encuentro, la mañana del sábado. 


\section{El tema de fondo: "Compromiso político: formas tradicionales y formas emergentes. El reto de la democracia participativa"}

Éste fue el título que dio a su ponencia ANTONIo Comín Oliveres, Licenciado en Ciencias Políticas, profesor de ESADE y Diputado en el Parlamento de Cataluña.

Partió de la convicción extendida de que mercado y democracia se requieren y complementan, para analizar hasta qué punto esta relación es correcta. Señaló más bien cómo el mercado contribuye a consolidar una cultura no democrática en la medida en que produce una fuerte fragmentación de la sociedad.

A esta fragmentación se ha querido responder por una doble vía, la comunitarista y la republicana, una vez desechada la solución de la democracia liberal, que se contenta con la gestión de los intereses en conflicto. La solución comunitarista busca construir valores comunes que garanticen una identidad compartida, pero lo hace desde una perspectiva conservadora invocando la tradición y con planteamientos prekantianos. En cambio, la solución republicana busca construir ese proyecto colectivo, no desde la tradición, sino desde la deliberación: deliberación y participación son dos elementos indisociables en toda democracia.

Este debate se agudiza con la actual crisis del sistema político, que responde a dos tipos de factores diferentes: el desencaje de lo político y lo económico como consecuencia de la globalización y el cambio de la cultura política. En efecto, la globalización está haciendo realidad lo que es consustancial al capitalismo: el mercado único. En estas condiciones el Estado no puede responder ya a las demandas sociales: por eso es cada vez más urgente construir un sistema democrático mundial, que tendría que articularse sobre unos organismos internacionales dotados de verdadero poder, una sociedad civil mundial más organizada y procesos de regionalización que condujeran a entes con verdadero poder político. Por su parte, el cambio de la cultura política, que es consecuencia de unos mayores niveles de educación y de información, no acaba de ser asimilado por unos partidos políticos, que siguen anclados en el modelo de élites ilustradas que se dan como tarea el mover a masas carentes de capacidad crítica.

Estas nuevas condiciones plantean la necesidad de recrear una democracia verdaderamente participativa. La democracia representativa se muestra insuficiente porque se reduce a una cesión del poder para que otros lo admi- 
nistren después de conquistarlo por estrategias más propios del mercado. Se impone activar mecanismos que devuelvan el poder a los ciudadanos según un modelo de democracia participativa.

Tres grupos de mecanismos son útiles para esta devolución del poder. Los primeros y más importantes son los movimientos sociales: a diferencia de los partidos políticos, trabajan con unos objetivos no limitados a la cadencia electoral y con una mayor atención a los principios (y no sólo a los intereses). Algunos mecanismos institucionales — tales como el referéndum o la iniciativa popular - también pueden facilitar a los ciudadanos la participación política. Por último, hay que hablar de la democratización de los partidos políticos (a través de limitación de mandatos, primarias, incorporación de personalidades independientes, etc.): pero, en todo caso, es éste un tema complejo en el que hay que avanzar con cautela.

A la exposición del ponente siguió un largo debate en el que se subrayó la necesidad de profundizar en muchos de los temas que habían sido mencionados: el mercado, su funcionamiento y su lógica; la globalización, su carácter revolucionario o contrarrevolucionario; el poder, la relación entre poder político legítimo y poderes fácticos; los valores de la democracia participativa como complemento de la democracia representativa. Se reflexionó también sobre el papel de la sociedad civil, y más concretamente de la Iglesia y la Compañía de Jesús como instancias críticas de la realidad política.

$* * *$

Concluido el debate sobre el tema central del encuentro, que ocupó toda la mañana del sábado, el resto de la reunión se dedicó a informar sobre el apostolado social en algunos países de Europa, a presentar algunas revistas relacionadas con el trabajo del grupo y a comunicaciones de varios de sus miembros. De todo ello damos cuenta a continuación.

\section{El apostolado social de la Compañía en Europa: algunas informaciones}

Intervino, en primer lugar, el P. MARK Rotsaert (Bruselas), Presidente de la Conferencia de Provinciales de la Compañía de Jesús en Europa. Se refirió sobre todo al grupo de trabajo sobre migraciones. Dicho grupo fue creado por la Conferencia de Provinciales de Europa, en su asamblea de Viena (octubre 2002). Como se sabe el trabajo con emigrantes y refugiados es considerado por la Compañía de Jesús como una de sus prioridades y 
a él se dedican personas y recursos considerables. El objetivo señalado al grupo creado era explorar vías concretas para la colaboración entre los jesuitas y sus compañeros laicos que trabajan con emigrantes y refugiados, para la coordinación de proyectos y para el intercambio de información. El grupo ha venido trabajando entre septiembre de 2003 y septiembre de 2005. Recientemente ha concluido su informe con algunas propuestas de acción a escala europea.

En principio estaba previsto presentar tres revistas de los jesuitas en la Asistencia del Sur de Europa (Italia, España y Portugal): la italiana Aggiornamenti Sociali, la española Revista de Fomento Social y la portuguesa Brotéria, pero sólo pudieron ser presentadas las dos últimas.

José Juan Romero (ETEA, Córdoba) se encargó de presentar la Revista de Fomento Social, de la que es director. Sería superfluo resumir en esta crónica la información que ofreció en su intervención por razones obvias. Pero sí es bueno aprovechar la ocasión para recordar que nuestra revista nació en 1946 en Madrid para promover y difundir el pensamiento social cristiano. Llegó a ser órgano oficioso de la Compañía de Jesús española en el campo social. En 1991 la Revista se trasladó a Córdoba (ETEA), su sede actual, con el compromiso de que mantuviese su carácter de reflexión ética cristiana sobre cuestiones sociales.

Al mismo tiempo se presentó el volumen Sociedad, política yeconomía en el cambio de siglo. Reflexiones de Fomento Social, que acababa de ser publicado por la Editorial Sal Terrae. En él se recogen 22 artículos editoriales de nuestra Revista, como una selección de todos los publicados entre 1996 y 2004.

La revista Brotéria, de los jesuitas portugueses, fue presentada por su director, HeRminio Rico (Lisboa). Brotéria se publica desde 1902 y ha pasado por distintas alternativas, incluso publicando simultáneamente varias series. Desde 1925 se publicó con el subtítulo de "Fe - ciências - letras" para subrayar el deseo de diálogo de la fe con la cultura de hoy. En la actualidad, desde 2002, ha cambiado ese subtítulo por el de "Cristianismo e Cultura", para destacar esta relación. Se publican 10 números al año y está dirigida a un público interesado en temas culturales y en su relación con la fe cristiana.

La información sobre las revistas fue complementada por otra sobre el apostolado social en los tres países citados.

El apostolado social de los jesuitas en Italia fue presentado por FRANCESCO DE LucciA (Roma), su coordinador. Explicó cómo la Compañía italiana ha dado el 
paso de constituir una federación (Jesuit Social Network), como asociación con carácter jurídico, que agrupa a todos los organismos que trabajan en el campo social (instituciones, grupos organizados, comunidades, pero no personas), ya sean de la Compañía, ya de inspiración ignaciana. Se pretende con ello eliminar la fragmentación y dispersión, de forma que se pueda trabajar con un proyecto común, siempre en el marco del proyecto apostólico de la Compañía de Jesús en Italia. En este momento hay 20 organismos federados (entre ellos, los dos centros sociales de Milán y Palermo), más 7 u 8 en proceso de federarse. La federación tiene un Consejo de Dirección, de 11 miembros, y un Consejo de Socios, donde están representados todos los organismos federados, con un miembro cada uno.

La información relativa al apostolado social de los jesuitas en Portugal corrió a cargo de Paulo Teia (Lisboa), que comenzó destacando cómo el nuevo Provincial, P. Nuno Gonçalves, había dado un fuerte impulso a la estructuración de este sector apostólico. Se ha elaborado un mapa de lo que se estaba haciendo y se ha celebrado después un encuentro con participación de jesuitas y laicos. Para la reorganización del apostolado social se ha creado una comisión formada por tres jesuitas y cinco laicos. Entre las primeras tareas que le han sido encomendadas se cuenta la de organizar el espacio parroquial (son diez las parroquias que mantienen los jesuitas en Portugal), estudiando cuáles se van a conservar y con qué estilo. Otro objetivo ha sido el de potenciar las comunidades de inserción con la apertura de una nueva comunidad en Rabo de Peixe (isla de San Miguel, Azores), que es una de las zonas más pobres de Europa.

A continuación Josep Messa (Barcelona) ofreció un breve informe de Eurojess, el grupo de jesuitas de diversos países de Europa que trabajan en ciencias sociales. Informó concretamente de su último encuentro, celebrado el pasado mes de agosto en Viena sobre el futuro de la democracia. Dio cuenta asimismo de la decisión tomada por la asamblea del grupo en el sentido de admitir miembros laicos en Eurojess, con tal que estén ligados a obras sociales de la Compañía.

Intervino, por último, en esta sesión informativa RAMIR PAMPOLS (Barcelona), que dio cuenta del encuentro de la Misión Obrera europea de Loyola, del 3 al 6 de agosto pasado. Su tema se formuló así: "Ser servidores de la misión de Cristo en la precariedad, en la inmigración y en la exclusión”. Asistieron 46 jesuitas de 8 países. 
Se anunció por fin la próxima Semana Social de los jesuitas, que tendrá lugar en Bratislava en el verano de 2007. Se ocupará como tema de la espiritualidad y el apostolado social.

\section{Otras comunicaciones}

Josep María Margenat (ETEA, Córdoba) presentó el Programa de Formación Política que apoyan varias instituciones de la Compañía de Jesús en España. Este programa tiene sus precedentes en diversas provincias jesuíticas españolas desde los años 1980. En la actualidad se ha concentrado en tres actividades: una semana de formación política (en julio de este año se ha celebrado en Salamanca la décimotercera), un encuentro con expertos y políticos (se celebrará en diciembre de 2005 la quinta edición en Córdoba), unos ejercicios espirituales con acompañamiento (se tuvieron por cuarto año consecutivo en agosto pasado en Granada).

El objetivo fundamental de este programa es la integración de la reflexión y la espiritualidad. Y está dirigido a universitarios y a jóvenes profesionales. Se da un relieve especial a la dimensión vocacional y a su proyección en un compromiso profesional y militante.

Alberto López Caballero (Madrid) ofreció una breve comunicación sobre "Antropología de la Doctrina Social de la Iglesia", que es un resumen de su colaboración en un libro, que está en prensa y que será publicado por AEDOS.

Josep Buades (del CeiM, Centro de Estudios para la Integración Social y Formación de Inmigrantes, de Valencia) dio cuenta de una experiencia reciente relacionada con la repatriación de emigrantes desde Marruecos a sus países de origen (subsaharianos). Contó cómo había sido encargado por la Compañía de Jesús para participar en una comisión de seguimiento de los convoyes organizados desde Marruecos para deportar a los emigrantes, con ocasión del salto masivo de las vallas instaladas en Ceuta y Melilla (fin de septiembre de este año). El objetivo de dicha comisión de seguimiento era controlar cómo se hacía esa deportación e informar a la opinión pública. El resultado ha sido detener esa primera forma de deportación, de todo punto intolerable por su crueldad e inhumanidad, pero se está a la espera de que se establezcan nuevas formas para hacerlo (preferentemente por vía aérea). 
La comunicación de LuIS ANoro (Zaragoza) ofreció algunas reflexiones personales para una nueva reformulación de la misión de la Compañía, que sugería el paso del binomio fe-justicia al binomio fe-inclusión.

Por último, Lluis Recolons (de Migrastudium, Barcelona) se hizo eco de la preocupación de algunos jesuitas en relación con la orientación de la cadena de emisoras COPE, que contribuye poco a crear un ambiente de respeto y diálogo en nuestro país.

\section{Sesión conclusiva}

En la sesión de clausura del encuentro - que tiene la función de ser la asamblea estatutaria del Grupo- se trataron algunas cuestiones de carácter general. Dos fueron las que retuvieron más atención: la relación de este Grupo con la Comisión Interprovincial de Apostolado Social de la Compañía y la conveniencia de invitar algunos laicos a este encuentro anual.

En cuanto a la organización del encuentro del próximo año se decidió que el tema fuese: "La exclusión y la inserción social: problemática de la integración de inmigrantes, violencia juvenil, etc.”. Se fijó también la fecha para el próximo encuentro, el año que viene. 